\title{
Use of Game Console for Rehabilitation of Parkinson's Disease
}

\author{
Levent Özgönenel ${ }^{1}$, Sultan Çağırıc1², Murat Çabalar², Gülis Durmuşoğlu ${ }^{3}$ \\ ${ }^{1}$ Department of Physical Medicine and Rehabilitation, İstanbul Bilim University School of Medicine, Florence Nightingale Hospital, İstanbul, Turkey \\ ${ }^{2}$ Department of Neurology, Bakırköy Dr. Sadi Konuk Training and Research Hospital, İstanbul, Turkey \\ ${ }^{3}$ Clinic of Physical Medicine and Rehabilitation, Güneşli Medicine Hospital, İstanbul, Turkey
}

Background: Parkinson's disease (PD) predisposes to falls due to postural instability and decreased coordination. Postural and coordination exercises could ameliorate the incoordination and decrease falls.

Aims: In this study, we explored the efficiency of a game console as an adjunct to an exercise program in treating incoordination in patients with PD.

Study Design: Case-control study.

Methods: In this single-blind, prospective clinical trial, rehabilitation with the Xbox (Microsoft; Washington, USA) game console was used as an adjunct to a standard rehabilitation program. Thirty-three patients with PD at stages 1-3 were enrolled in the study. All patients received the threetimes weekly exercise program and electrotherapy to back and hip extensors for 5 weeks. Study patients played catch the ball and obstacle games on the Xbox in addition to the standard exercise program. Patients were evaluated based on the scores from the Timed Up-and-Go Test, the Berg Balance Scale (BBS), and the Unified Parkinson's Disease Rating Scale-II (UPDRS-II). Post-treatment scores were compared between groups.

Results: Thirty-three patients were enrolled in the study (15 in the game-console group, and 18 controls). Patients in both groups had improvements in all scores. The end-oftreatment scores were significantly better in the study group compared to the control group in all parameters: UPDRS ( $10 \pm 5$ versus $16 \pm 6, p=0.002$ ), BBS ( $53 \pm 4$ versus $47 \pm 8$, $\mathrm{p}=0.004)$, and TUG ( $11 \pm 4$ seconds versus $20 \pm 8$ seconds, $\mathrm{p}<0.001)$.

Conclusion: Game-exercise with a game-console was noted to be a significant adjunct to the rehabilitation program in patients with PD in this study.

Keywords: Parkinson's disease, rehabilitation, game console
Parkinson's disease (PD) predisposes to falls due to postural instability and freezing. Improving gait and balance and thus preventing falls responds poorly to pharmacological treatment, and is therefore a major therapeutic challenge in PD $(1,2)$. Rehabilitation may play a key role in the management of gait and balance disorders of PD. Exercise therapy as part of rehabilitation has positive effects on physical functioning, quality of life and balance in patients with PD (3). Postural and coordination exercises could ameliorate the incoordination and decrease falls (4). In recent years, the therapeutic role of video game consoles has also been explored in rehabilitation trials (5). In this study, we examined the efficiency of video game consoles as an adjunct to an exercise program in improving clinical measures of balance in patients with PD.

\section{MATERIALS AND METHODS}

\begin{abstract}
Design
In this single-blind, prospective clinical trial, rehabilitation with the Xbox video game console was compared with the standard rehabilitation program.
\end{abstract}

\section{Participants}

Patients with idiopathic PD at Hoehn and Yahr stages 1-3 were enrolled in the study. Patients were excluded if they had sensory, visual, cognitive and/or praxis impairment. Cognitive impairment was assessed by the Mini Mental State Examina-

This study was presented at the $9^{\text {th }}$ International Society of Physical and Rehabilitation Medicine Congress, 19- 23 June 2015, Berlin, Germany.

Address for Correspondence: Dr. Levent Özgönenel, Department of Physical Medicine and Rehabilitation, İstanbul Bilim University School of Medicine, Florence

Nightingale Hospital, İstanbul, Turkey

Phone: +905053946184e-mail: levento26@yahoo.com

Received: 29 September $2014 \quad$ Accepted: 21 November 2015

Available at www.balkanmedicaljournal.org

Cite this article as:

Özgönenel L, Çağırıcı S, Çabalar M, Durmuşoğlu G. use of game console for rehabilitation of Parkinson's disease. Balkan Med J 2016;33:396-400 
tion, with a cut off of 23. Patients were excluded if they had changed their PD medication before the study. Only participants who could ambulate at least 30 meters without an assistive device and stand unassisted for at least 15 minutes were enrolled in the study. The participants had to have no prior experience of using a video game console and should not have attended any other rehabilitation prior to the study. Patients were assigned to the study groups by an independent researcher based on nonconsecutive clinic appointment number (first patient into the control group, second patient into the study group, and so on).

The study was approved by the ethics committee of İstanbul Kemerburgaz University. The patients were recruited at the rehabilitation unit of Medical Park Hospital, Department of Physical Medicine and Rehabilitation, İstanbul Kemerburgaz University School of Medicine, from August 2013 to February 2014. Informed patients consents were obtained.

Interventions: All patients were on dopaminergic replacement therapy during the study period. All patients were given the exercise program, hot pack and electrotherapy. Before the exercise program, a hot pack was applied for 20 minutes to relieve joint stiffness and rigidity. Electrical stimulation was applied to extensor muscle groups of the knee and trunk, using programs for strengthening and deconditioning in CefarCompex Rehab 400 device (DJO Global; CA, USA).

After 5 minutes of warming, patients completed posture, balance and stretching exercises of approximately 60 minute duration. Posture exercise involved correcting their posture facing a full length mirror. Balance exercise program involved different tasks during standing. Gait practice included initiation and termination of gait, changing direction and negotiating different obstacles. Strengthening exercises included using free weights and graded resistance bands. The experimental group also received an Xbox ${ }^{\mathrm{TM}}$ (Microsoft; Washington, USA) training session. Each group of patients received this exercise program 3 times a week for 5 weeks.

Xbox training and games: Physiotherapists provided instructions to the patients on games, and observed patients during games for safety. After training, patients were asked to play twice for practice. Only patients who could play the Xbox were recruited to the experimental group. Three games in Kinect adventures were selected: Reflex Ridge, 20,000 Leaks and River Rush. In 20,000 Leaks, the player's avatar is in a glass cube underwater, and tries to plug the cracks in the cube caused by sea animals. In River Rush, the player stands on a raft and tries to pick up the adventure pins scattered throughout the winding rapids while trying to steer the raft. Reflex Ridge is played on a moving platform in an environment similar to a wooden roller coaster or mine cart. The player races on a platform, jumps over hurdles, and leans away from obstacles to avoid hitting his/her head on low beams. The Reflex Ridge was used for static balance and for gaining coordination in using extremities. The River Rush and 20,000 Leaks games were used for attaining a dynamic balance (6). Patients in the experimental group played all three games at every training session (three games per session, two trials of each game). Subjects were allowed to play only at Beginner level. The duration of the game was set and did not vary (River Rush 2 minutes, Reflex Ridge and 20,000 Leaks both 3 minutes), but the scores varied per patient.

Outcomes: Both groups were assessed in the mornings before and after the rehabilitation program. Berg balance scale (BBS) and Timed Up-and-Go (TUG) tests were used for assessing balance as part of the primary outcome. BBS comprises 14-items that measure static and dynamic balance, with higher scores indicating improved balance. The secondary outcome measured the change in daily activities. To assess the performance of daily living, we utilized section II of the Unified Parkinson Disease Rating Scale (UPDRS-II), which includes speech, salivation, swallowing, handwriting, handling, dressing, hygiene, changing position in bed, falling, freezing, walking, tremor and sensory complaints. This scale has been validated in Turkish patients with PD (7). Fall frequency was also recorded before and after the program.

Sample size calculation: Sample size calculation was based on the similar studies in the literature, with a minimum number of subjects per group estimated to be 15 to attain a power level of $90 \%$ (alpha $=0.05)$.

\section{Statistical analysis}

PASW21.0 (Predictive Analytics Software, SPSS Inc.; Chicago, USA) was used for statistical analysis. Paired t-test was used to compare pre- and post-scores. Mann-Whitney U and Chi-Squared tests were employed for the baseline comparison of the groups and also post-scores of study and control groups. Improvement of the scores (expressed as \% improvement) were calculated as below:

UPDRS-II $=$ (pre-score - post-score $) \times 100 /$ pre-score

BBS $=($ post-score - pre-score $) \times 100 /$ pre-score

TUG $=$ (pre-score - post-score $) \times 100 /$ pre-score

These ratios were also compared using the Mann-Whitney test.

\section{RESULTS}

Of the 47 patients with PD, 33 were enrolled in the study (15 in game-console group, 18 controls). The demographic characteristics of both groups are summarized in Table 1 . Whereas the groups were matched age- and sex-distribution wise, and the baseline UPDRS-II scores were close $(\mathrm{p}=0.052)$, 
TABLE 1. Demographic and functional characteristics of the study and control groups

\begin{tabular}{|c|c|c|c|c|}
\hline & $\begin{array}{c}\text { Study } \\
\text { Group } \\
\mathrm{n}=15\end{array}$ & $\begin{array}{c}\text { Control } \\
\text { Group } \\
n=18\end{array}$ & $\begin{array}{l}\text { Total } \\
\mathbf{n}=\mathbf{3 3}\end{array}$ & $\begin{array}{c}\text { Comparison } \\
\text { between } \\
\text { study and } \\
\text { control } \\
\text { groups }\end{array}$ \\
\hline Male:Female Ratio & $2: 1$ & $2: 1$ & $2: 1$ & $\mathrm{p}=1.0$ \\
\hline Median age & 64 & 65 & 65 (range 46-78) & $\mathrm{p}=0.107$ \\
\hline $\begin{array}{l}\text { Hoehn and } \\
\text { Yahr Staging }\end{array}$ & $\begin{array}{c}\text { Stage } 1 n=3 \\
\text { Stage } 2 n=10 \\
\text { Stage } 3 n=2\end{array}$ & $\begin{array}{l}\text { Stage } 1 n=4 \\
\text { Stage } 2 n=6 \\
\text { Stage } 3 n=8\end{array}$ & $\begin{array}{l}\text { Stage } 1 n=7 \\
\text { Stage } 2 n=16 \\
\text { Stage } 3 n=10\end{array}$ & $\mathrm{p}=0.105$ \\
\hline $\begin{array}{l}\text { Duration of PD } \\
\text { in years Median } \\
\text { (range) }\end{array}$ & $4.0(1-10)$ & $3.5(1-22)$ & $4.0(1-22)$ & $\mathrm{p}=0.331$ \\
\hline $\begin{array}{l}\text { Baseline } \\
\text { UPDRS-II Score* }\end{array}$ & $14 \pm 6$ & $19 \pm 7$ & $17 \pm 7$ & $\mathrm{p}=0.052$ \\
\hline $\begin{array}{l}\text { Baseline } \\
\text { BBS Score** }\end{array}$ & $48 \pm 7$ & $41 \pm 10$ & $45 \pm 9$ & $\mathrm{p}=0.027$ \\
\hline $\begin{array}{l}\text { Baseline } \\
\text { TUG in seconds*** }\end{array}$ & $16 \pm 9$ & $28 \pm 21$ & $23 \pm 17$ & $\mathrm{p}=0.002$ \\
\hline $\begin{array}{l}\text { *Unified Parkinson Dis } \\
\text { **Berg balance scale } \\
\text { ***Timed Up-and-Go }\end{array}$ & $\begin{array}{l}\text { sease Rating Scal } \\
\text { vas used. } \\
\text { Test was used. }\end{array}$ & was used. & & \\
\hline
\end{tabular}

TABLE 2. Changes in evaluation scores before and after the treatment period, given as mean \pm standard deviation

\begin{tabular}{|c|c|c|c|}
\hline Test Parameter & $\begin{array}{c}\text { Study Group } \\
n=15\end{array}$ & $\begin{array}{c}\begin{array}{c}\text { Control Group } \\
n=18\end{array} \\
\end{array}$ & $\begin{array}{l}\text { Total } \\
\mathbf{n}=\mathbf{3 3}\end{array}$ \\
\hline \multirow[t]{3}{*}{ UPDRS-II Score* } & Pre $14 \pm 6$ & Pre $19 \pm 7$ & Pre $17 \pm 7$ \\
\hline & Post $10 \pm 5$ & Post $16 \pm 6$ & Post $13 \pm 6$ \\
\hline & $(\mathrm{p}<0.001)$ & $(p=0.002)$ & $(\mathrm{p}<0.001)$ \\
\hline \multirow[t]{3}{*}{ BBS Score** } & Pre $48 \pm 7$ & Pre $41 \pm 10$ & Pre $45 \pm 9$ \\
\hline & Post $53 \pm 4$ & Post $47 \pm 8$ & Post $50 \pm 7$ \\
\hline & $(\mathrm{p}<0.001)$ & $(\mathrm{p}=0.002)$ & $(\mathrm{p}<0.001)$ \\
\hline \multirow[t]{3}{*}{ TUG in seconds $* * *$} & Pre $16 \pm 9$ & Pre $28 \pm 21$ & Pre $23 \pm 17$ \\
\hline & Post $11 \pm 4$ & Post $20 \pm 8$ & Post $16 \pm 8$ \\
\hline & $(p=0.007)$ & $(\mathrm{p}=0.089)$ & $(p=0.014)$ \\
\hline
\end{tabular}

*Unified Parkinson Disease Rating Scale was used.

**Berg balance scale was used.

***Timed Up-and-Go Test was used.

the control group had a significantly lower baseline BBS score $(\mathrm{p}=0.027)$ and the baseline mean TUG test took significantly longer compared to the study group ( $\mathrm{p}=0.002)$.

Patients in both groups had improvements in UPDRS-II, BBS, and TUG scores, as summarized in Table 2. The end-oftreatment scores were significantly better in the study group compared to the control group in all parameters: UPDRSII ( $10 \pm 5$ versus $16 \pm 6, \mathrm{p}=0.002)$; BBS $(53 \pm 4$ versus $47 \pm 8$, $\mathrm{p}=0.004)$; and TUG (11 \pm 4 seconds versus $20 \pm 8$ seconds, $\mathrm{p}<0.001$ ).
TABLE 3. Comparison of improvement in assessment scores among groups, including all patients, given as mean \pm standard deviation

\begin{tabular}{lccc}
\hline $\begin{array}{l}\text { \% Improvement } \\
\text { ratios }\end{array}$ & $\begin{array}{c}\text { Study Group } \\
\mathbf{n}=\mathbf{1 5}\end{array}$ & $\begin{array}{c}\text { Control Group } \\
\mathbf{n}=\mathbf{1 8}\end{array}$ & $\begin{array}{c}\text { Significance level } \\
\text { (one-tailed) }\end{array}$ \\
\hline UPDRS-II* & $33 \pm 20$ & $16 \pm 16$ & $\mathrm{p}=0.007$ \\
BBS** & $12 \pm 11$ & $21 \pm 43$ & $\mathrm{p}=0.845$ \\
TUG*** & $24 \pm 18$ & $16 \pm 24$ & $\mathrm{p}=0.067$ \\
\hline
\end{tabular}

*Unified Parkinson Disease Rating Scale was used.

**Berg balance scale was used.

***Timed Up-and-Go Test was used.

TABLE 4. Comparison of improvement in assessment scores among groups, including only patients at Hoehn and Yahr stages 1 and 2, given as mean \pm standard deviation

\begin{tabular}{lccc}
\hline \% Improvement ratios & $\begin{array}{c}\text { Study Group Control Group Significance level } \\
\mathbf{n}=\mathbf{1 3}\end{array}$ & $\mathbf{n = 1 0}$ & (one-tailed) \\
\hline UPDRS-II* & $34 \pm 21$ & $9 \pm 12$ & $\mathrm{p}=0.003$ \\
BBS** & $8 \pm 5$ & $4 \pm 2$ & $\mathrm{p}=0.049$ \\
TUG*** & $20 \pm 17$ & $6 \pm 10$ & $\mathrm{p}=0.026$ \\
\hline
\end{tabular}

*Unified Parkinson Disease Rating Scale was used.

**Berg balance scale was used.

****Timed Up-and-Go Test was used.

We also compared the improvement in scores of the abovementioned scores, and observed that the actual changes in scores were significantly better in the study group only for the UPDRS-II scores $(33 \pm 20 \%$ improvement among study subjects versus $16 \pm 16 \%$ improvement among control subjects, $p=0.007$ ). Although there was an improvement in the other parameters as well, the ratio was not different between groups. After excluding patients at Hoehn and Yahr stage 3, we observed that the study group showed significantly better improvement in all parameters. The improvement ratios are summarized in Table 3, 4 .

\section{Fall frequency}

$68.8 \%$ of the control group patients and $31.3 \%$ of the study group patients had falls before the treatment program $(p=0.166)$. No falls were seen in any of the subjects following the treatment program.

\section{DISCUSSION}

Various studies have previously shown the efficacy of video game consoles in rehabilitation. Xbox ${ }^{\mathrm{TM}}$ Kinect has been used for the rehabilitation of patients with hemiplegia, cerebral palsy and burns (8-10).

Other studies and projects have also tackled the therapeutic use of video games for rehabilitation in PD $(11,12)$. Rehabili- 
tation programs that include task-oriented and visual-auditory feedback are effective in improving daily living activities (13). The games used in the current study were not originally designed for rehabilitation, but they were still effective because they were able to provide such feedback to the patients.

Xbox $^{\text {TM }}$ Kinect creates an avatar of the player using infrared camera sensors, so players can join the game without any controller, attachment or balance board. The avatar moves with the player so the player can see his posture and movement in real-time. Being free of attachments may be an important factor because in a study that investigated the effect of the Nintendo Wii ${ }^{\text {TM }}$ (Nintendo; WA, USA) on daily living performance in PD, a lack of improvement in Fullerton advanced balance and TUG scores was explained by the participants' fear of falling (14).

In our study, end-of-treatment UPDRS-II scores were significantly better in the study group compared to the control group, with a $33 \%$ improvement in study subjects compared to $16 \%$ in control subjects. This improvement in scores can also predict improvement in daily living activities. BBS and TUG scores improved in both groups, but the patients in the control group had worse baseline BBS and TUG scores. After excluding patients at Hoehn and Yahr stage 3, we found that the study subjects showed a more pronounced improvement in all scores. The Hoehn and Yahr scale mostly evaluates postural instability and motor impairment, and advanced stages correlate with dopaminergic loss, motor decline, and deterioration of quality of life $(15,16)$. Patients with advanced PD have difficulty learning skills or new tasks (17). This may mean that patients at earlier stages of PD may benefit more from incorporating video game console exercises to their rehabilitation.

Participants in our study verbalized that they enjoyed training with the game console. This positive effect may improve adherence to an otherwise monotonous rehabilitation program, and should be examined in future studies. In addition, patients who can afford to could purchase a game console to further exercise at home.

\section{Study limitations}

There are two important limitations of our study. First, the patients in the control group had higher stages of disease and worse pre-treatment scores for TUG and BBS, which could have biased the results. Second, we did not evaluate the longterm benefit of video game console use.

$\mathrm{Xbox}^{\mathrm{TM}}$ Kinect is efficient as an intervention for the rehabilitation of patients with PD. Further research is needed to examine the long-term beneficial effects of this therapeutic modality. Cost, the quality of pleasurable experience with $\mathrm{Xbox}^{\mathrm{TM}}$ Kinect, and its help in adherence to a training programs should also be examined in future studies.
Ethics Committee Approval: The study was approved by the ethic committee of İstanbul Kemerburgaz University.

Informed Consent: Written informed consent was obtained from the patients who participated in the study.

Peer-review: Externally peer-reviewed.

Author contributions: Concept - L.Ö., S.Ç.; Design - L.Ö.; Supervision - L.Ö.; Resource - L.Ö., S.Ç., M.Ç., G.D.; Materials - L.Ö.; Data Collection and/or Processing - L.Ö., S.Ç., M.Ç., G.D.; Analysis and/or Interpretation - L.Ö., S.Ç., M.Ç., G.D.; Literature Search L.Ö., S.Ç.; Writing - L.Ö., S.Ç., M.Ç., G.D.; Critical Reviews - L.Ö.

Acknowledgements: Authors would like to thank Dr. Bülent Özgönenel for help of editing English in the manuscript.

Conflict of Interest: No conflict of interest was declared by the authors.

Financial Disclosure: The authors declared that this study has received no financial support.

\section{REFERENCES}

1. Dibble LE, Christensen J, Ballard DJ, Foreman KB. Diagnosis of fall risk in Parkinson disease: an analysis of individual and collective clinical balance test interpretation. Phys Ther 2008;88:323-32.

2. Dibble LE, Lange M. Predicting falls in individuals with Parkinson disease: a reconsideration of clinical balance measures. $J$ Neurol Phys Ther 2006;30:60-7.

3. Paul SS, Sherrington C, Canning CG, Fung VS, Close JC, Lord SR. The relative contribution of physical and cognitive fall risk factors in people with Parkinson's disease: a large prospective cohort study. Neurorehabil Neural Repair 2014;28:282-90.

4. Lee G. Effects of training using video games on the muscle strength, muscle tone, and activities of daily living of chronic stroke patients. J Phys Ther Sci 2013;25:595-7.

5. Pompeu JE, Mendes FA, Silva KG, Lobo AM, Oliveira Tde P, Zomignani AP, et al. Effect of Nintendo Wii-based motor and cognitive training on activities of daily living in patients with Parkinson's disease: a randomised clinical trial. Physiotherapy 2012;98:196-204.

6. Cork J. Like Jumping And Ducking? Kinect Adventures Will Blow Your Mind 2010 [cited 2015]. Available from:http://www. gameinformer.com/b/news/archive/2010/06/17/like-jumpingand-ducking-kinect-adventures-will-blow-your-mind.aspx.

7. Akbostancı M, Balaban H, Atbaşoğlu C. Birleşik Parkinson Hastalığı Değerleme Ölçeği Motor Muayene Bölümü ve Anormal İstemsiz Hareketler Ölçeği'nin değerlendiriciler arası güvenilirlik çalışması. Parkinson Hastalı̆̆ ve Hareket Bozuklukları Dergisi 2000;3:7-13. 
8. Luna-Oliva L, Ortiz-Gutierrez RM, Cano-de la Cuerda R, Piedrola RM, Alguacil-Diego IM, Sanchez-Camarero C, et al. Kinect Xbox 360 as a therapeutic modality for children with cerebral palsy in a school environment: a preliminary study. $\mathrm{Neu}$ roRehabilitation 2013;33:513-21.

9. Parry I, Carbullido C, Kawada J, Bagley A, Sen S, Greenhalgh D, et al. Keeping up with video game technology: Objective analysis of Xbox Kinect and PlayStation 3 Move for use in burn rehabilitation. Burns 2014;40:852-9.

10. Sin $\mathrm{H}$, Lee G. Additional virtual reality training using Xbox Kinect in stroke survivors with hemiplegia. Am J Phys Med Rehabil 2013;92:871-80.

11. Developing movement-based computer games for Parkinson's 2012 Parkinson's UK]. Available from: http://www.parkinsons. org.uk/content/developing-movement-based-computer-gamesparkinsons.

12. Alvarez M, Grogan P. Connecting with Kinect(R) To Improve Motor and Gait Function in Parkinson Disease. Neurology 2012;78.
13. Giggins OM, Persson UM, Caulfield B. Biofeedback in rehabilitation. J Neuroeng Rehabil 2013;10:60.

14. Bieryla KA, Dold NM. Feasibility of Wii Fit training to improve clinical measures of balance in older adults. Clin Interv Aging 2013;8:775-81.

15. Goetz CG, Poewe W, Rascol O, Sampaio C, Stebbins GT, Counsell C, et al. Movement Disorder Society Task Force on Rating Scales for Parkinson's D. Movement Disorder Society Task Force report on the Hoehn and Yahr staging scale: status and recommendations. Mov Disord 2004;19:1020-8.

16. Martinez-Martin P, Rodriguez-Blazquez C, Mario A, Arakaki T, Arillo VC, Chana P, et al. Parkinson's disease severity levels and MDS-Unified Parkinson's Disease Rating Scale. Parkinsonism Relat Disord 2015;21:50-4.

17. Morris ME. Locomotor training in people with Parkinson disease. Phys Ther 2006;86:1426-35. 